\title{
Late Glacial and Holocene vegetation and climate history of an alpine wetland on the Qinghai-Tibetan Plateau
}

\author{
Demei LIU ${ }^{1,2, *}$, Guichen $\mathrm{CHEN}^{2}$, Zhongping $\mathrm{LAI}^{3,4}$, Haicheng WEI ${ }^{3}$, Guoying ZHOU ${ }^{2}$ and Min PENG ${ }^{2}$ \\ 1 University of Chinese Academy of Sciences, 19 Yuquan Rd., Beijing 100049, China \\ 2 Northwest Institute of Plateau Biology, Chinese Academy of Sciences, 23 Xinning Rd., Xining 810008, China \\ 3 CAS Key Laboratory of Salt Lake Resources and Chenistry, Qinghai Institute of Salt Lakes, Chinese Academy of Sci- \\ ences, 18 Xinning Rd., Xining 810008, China \\ 4 Key Laboratory of Qinghai-Tibetan Plateau Environment and Resource (MOE), School of Life and Geographic Science, \\ Qinghai Normal University, 38 West Wusi, Xining 810008, China
}

Liu D., Chen G., Lai Z., Wei H., Zhou G. and Peng M. (2013) Late Glacial and Holocene vegetation and climate history of an alpine wetland on the Qinghai-Tibetan Plateau. Geological Quarterly, 57 (2): 261-268, doi: 10.7306/gq.1096

This study provides a vegetation and climate history of an alpine wetland in the centre of China's Qinghai-Tibetan Plateau (QTP) over the last $14.8 \mathrm{ka}$. High resolution climate proxies include vegetation (pollen), geochemical $\left(\mathrm{Ba}, \mathrm{Rb}, \delta^{13} \mathrm{C}\right)$ and physical (particle size and magnetic susceptibility) data; optically stimulated luminescence (OSL) and AMS radiocarbon dating were used to reconstruct the environmental changes in the wetland ecosystem. Based on physical and geochemical proxies, the sucession divided into five stratigraphic units encompassing time intervals of 14.76-14.31, 14.31-13.17, $13.17-4.47,4.47-0.51$ and $0.51-0 \mathrm{ka}$. The average sedimentation rate of all these units was $0.098 \mathrm{~mm} / \mathrm{a}$. The study showed that this ecosystem was sensitive to climate change.

Keywords: Late Glacial, Holocene, Qinghai-Tibetan Plateau, alpine wetland, optically stimulated luminescence, pollen analysis.

\section{INTRODUCTION}

The Qinghai-Tibetan Plateau (QTP) has important effects on both local and global climate. Many palaeoenvironmental studies have constrains the nature of climate change since the last interglacial period across the QTP (Zhu et al., 2002; Wu et al., 2007; Wang et al., 2009; Zhu et al., 2009, 2010). However, a general and internationally acceptable framework has still not been established and the mechanism of climate change remains unclear (Lister et al., 1991; Wang, 2005; Herzschuh et al., 2006; Wu et al., 2007; Zhao et al., 2008; Liu et al., 2010; Bian et al., 2011). Wetlands serve as archives for atmospheric chemical deposition and may provide useful records of spatial and temporal patterns of environmental and constrain rates and amounts of deposition (Mesnage et al., 2002; Kim and Kim, 2010; Margielewski et al., 2011). Alpine wetland covers a total area of $47,000 \mathrm{~km}^{2}$ on the QTP (Zhao, 1999).

The past climate can be reconstructed using a combination of different types of proxy records (such as ice cores, tree rings, fossil pollen, boreholes, corals, and lake and ocean sed-

\footnotetext{
* Corresponding author: liudemei83@163.com
}

Received: April 19, 2012; accepted: January 9, 2013; first published online: May 21, 2013 iments). Carbonate in late Holocene marsh deposits is formed under isotopic equilibrium and reflects the isotopic composition of the environmental water, and thus the $\delta^{13} \mathrm{C}$ in marsh deposits is a proxy of continental climate. Total Organic Carbon (TOC) is an index of organic productivity and is supported by the $\mathrm{Mg} / \mathrm{Ca}$ ratio, which is related to precipitation and temperature. The objective of this study was to evaluate an alpine wetland as an archive of past environmental conditions by attempting to reconstruct the vegetation and climate history from multiple sedimentary proxies. In the current study, Optically Stimulated Luminescence (OSL) and the Accelerator Mass Spectrometer (AMS) techniques were combined to establish the chronology and to derive sediment accumulation rates. A suite of geochemical $\left(\mathrm{Rb}, \mathrm{Ba}, \delta^{13} \mathrm{C}\right.$ ) and physical (particle size, magnetic susceptibility) proxies were measured to assess past climate conditions.

\section{MATERIALS AND METHODS}

\section{STUDY AREA}

The study area is located in Maqin County (Fig. 1) of the Quoluo Zang Autonomous Prefecture of Qinghai Province, China. The study site $\left(\mathrm{N} 34^{\circ} 28^{\prime}, \mathrm{E} 100^{\circ} 09^{\prime}\right)$ has an altitude of $3760 \mathrm{~m}$ above sea level and an annual average air temperature of $\sim-4^{\circ} \mathrm{C}$ with no frost-free season. The average annual precipi- 

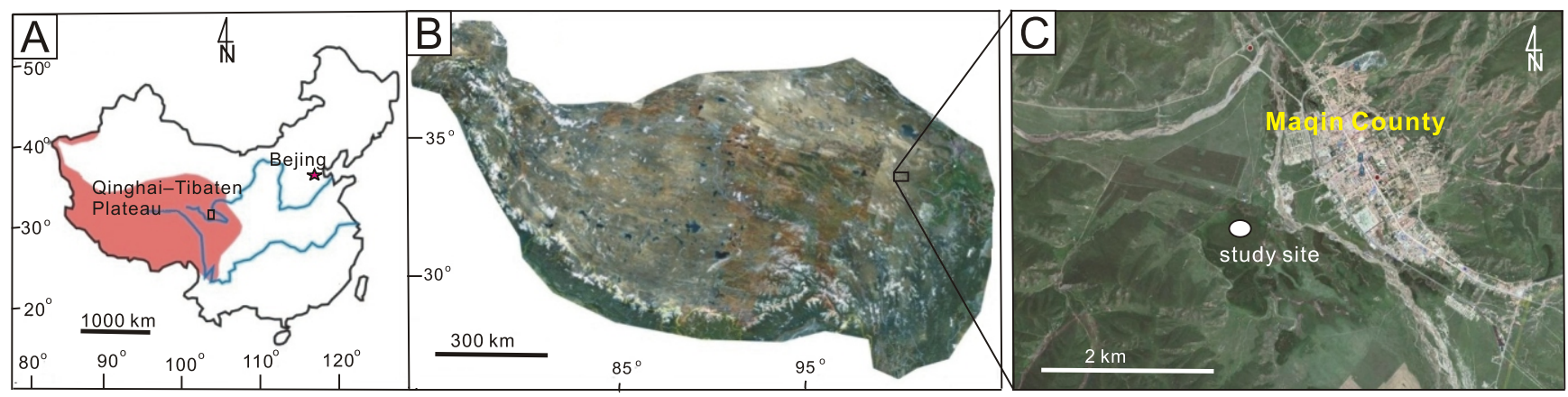

Fig. 1. Location of the study region and site

A - location of the study region (black square) in China; B - location of the study region (black square) on the Qinghai-Tibetan Plateau; C - location of the study site (white dot) in Maqin County

Table 1

Characters of modern plants communities in alpine wetland

\begin{tabular}{|l|c|c|c|c|}
\hline \multicolumn{1}{|c|}{ Dominant species } & $\begin{array}{c}\delta^{13} \mathrm{C} \\
{[\%]}\end{array}$ & $\begin{array}{c}\text { Coverage } \\
{[\%]}\end{array}$ & $\begin{array}{c}\text { Height } \\
{[\mathrm{cm}]}\end{array}$ & $\begin{array}{c}\text { Dominance } \\
{[\%]}\end{array}$ \\
\hline Kobresia tibetica & $-27.9 \pm 0.003$ & $41.67 \pm 10.5$ & $51.83 \pm 5.5$ & $24.43 \pm 3.8$ \\
\hline Puccinellia distans & $-26.6 \pm 0.002$ & $45 \pm 8$ & $18.5 \pm 4.3$ & $20.06 \pm 4.4$ \\
\hline Carex tristachya & $-27.6 \pm 0.005$ & $5.17 \pm 1.2$ & $17.33 \pm 6.2$ & $8.16 \pm 2.1$ \\
\hline Caltha scaposa Hook & $-23.7 \pm 0.003$ & $2.5 \pm 0.8$ & $5.5 \pm 1.4$ & $5.47 \pm 1.9$ \\
\hline Ranunculus pulchellus & $-25.3 \pm 0.004$ & $1.5 \pm 0.3$ & $13.17 \pm 2.3$ & $5.75 \pm 1.4$ \\
\hline Potentila anserina & $-26.2 \pm 0.005$ & $6.16 \pm 2.1$ & $14.15 \pm 2.7$ & $6.55 \pm 1.5$ \\
\hline
\end{tabular}

tation is $513 \mathrm{~mm}$ and the average annual pan-evaporation is approximately $3000 \mathrm{~mm}$. A total of 20 species of higher plants belonging to 9 families and 18 genera in the sample plots has been identified. The dominant families include Gramineae (3 genera, 3 species), Cyperaceae (4 genera, 4 species), Compositae (2 genera, 4 species), Ranunculaceae (3 genera, 3 species). Scrophulariaceae, Liliaceae, Umbelliferae and Rosaceae include one genus and one species, respectively. The main characteristics of the dominant species (dominance $>5 \%$ ) are summarized in Table 1 .

\section{MATERIALS AND PREPARATION TECHNIQUES}

SAMPLING

The sediment push-core sample $(150 \mathrm{~cm}$ long) was collected with an iron spade from a wetland at Maqin in October 2010. OSL samples were collected at depths of $24,54,85,113$ and $144 \mathrm{~cm}$. The lithostratigraphy of the deposits in the core is shown in Figure 2. Based on sedimentary texture and vertical color variation, three sedimentary units are identified: $0-52 \mathrm{~cm}$, red loam (young soil); 52-90 cm, gravel layer (fluvial deposits); 90-150 cm, gray soil (old wetland soil). Core subsamples were sliced into $3 \mathrm{~cm}$ sections and stored in plastic bags for further analysis.

\section{LABORATORY ANALYSES}

TOC was determined with an organic carbon analytical instrument (JingDao 5000A, Japan), the total nitrogen content (TN) was measured with an elemental analyzer (Vario EL III,
Germany), the magnetic susceptibility $\left(\times 10^{-6} \mathrm{~m}^{3} / \mathrm{kg}\right.$, SI system) was measured using a magnetic susceptibility instrument (MS2, UK), and the TOC/TN was calculated by mass. The carbon stable isotopes were measured using a Finnigan MAT Delta Plus mass spectrometer coupled with a Flash EA $1112 \mathrm{el}-$ emental analyzer. Stable isotope results were expressed as per mil (\%o) deviation relative to the VPDB standard and the reproducibility of duplicate analyses was $\pm 1 \%$.

For radiocarbon dating, a sample of plant material remain (at $144 \mathrm{~cm}$ depth) was chosen. AMS ${ }^{14} \mathrm{C}$ dating of the bulk sample was performed at the Heavy lon Institute of Beijing University in China.

In OSL dating, raw samples were treated with $38 \% \mathrm{H}_{2} \mathrm{O}_{2}$, then with $10 \% \mathrm{HCl}$ to remove organic materials and carbonates. Grains between 38 and $63 \mu \mathrm{m}$ were selected by dry sieving. The 38-63 $\mu \mathrm{m}$ particle fraction was treated with $35 \%$ $\mathrm{H}_{2} \mathrm{SiF}_{6}$ acid for about two weeks to remove feldspars (Lai, 2010), then the quartz grains were washed with $10 \% \mathrm{HCl}$ and then with water.

After infrared light checking, samples that showed obvious IRSL signals under infrared light were re-treated with $\mathrm{H}_{2} \mathrm{SiF}_{6}$, and checked again with IRSL to avoid age underestimation (Lai et al., 2008). Finally, the pure quartz extracts were mounted in the central parts $(\sim 0.5 \mathrm{~mm}$ in diameter) of stainless discs (10 $\mathrm{mm}$ in diameter) with silicone oil.

All luminescence measurements, beta irradiation and preheat treatments were carried out on a TL/OSL reader (Risø $T L / O S L D A-20$ ) coupled with a ${ }^{90} \mathrm{Sr} /{ }^{90} \mathrm{Y}$ beta source. The OSL signal was detected with a $7.5 \mathrm{~mm}$ thick Hoya U-340 glass filter. OSL signals were measured for $40 \mathrm{~s}$ at a sample temperature of $130^{\circ} \mathrm{C}$. The quartz OSL was stimulated with blue diodes 


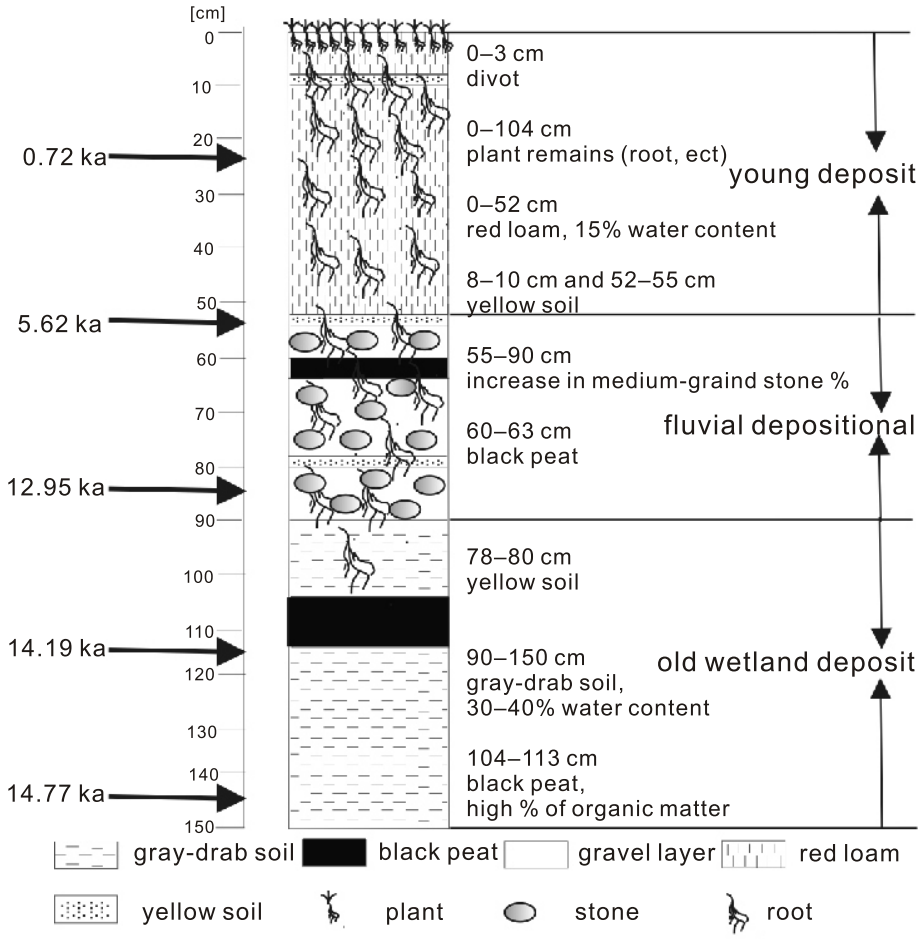

Fig. 2. Lithostratigraphy of the deposits in the core

$(\lambda=470 \pm 20 \mathrm{~nm})$. Equivalent dose $\left(D_{\mathrm{e}}\right)$ was determined with single aliquot regenerative-dose (SAR) protocol (Murray and Wintle, 2000; Lai et al., 2007). After background subtraction, signals from the first $0.64 \mathrm{~s}$ stimulation were integrated for growth curve construction. An $\alpha$-value of $0.035 \pm 0.003$ was adopted for quartz (Lai et al., 2007).

The contents of $U$, Th and $K$ were measured using neutron activation analysis (NAA). The cosmic ray dose was estimated for each sample as a function of depth, altitude and geomagnetic latitude (Prescott and Hutton, 1994).

\section{POLLEN ANALYSIS}

Pollen samples were sieved, and then were treated with $10 \% \mathrm{HCL}$ and $10 \% \mathrm{KOH}$, for floatation in a heavy liquid solution $(\mathrm{KI}+\mathrm{HI}+\mathrm{Zn})$ with a specific gravity of about 1.9 to extract pollen from sediments (Wei et al., 2010). Pollen taxa were identified under an optical microscope at $400 \times$ magnification. The pollen percentages and influx diagrams were constructed with Tilia software. The results of the pollen analysis were presented as a percentage pollen diagram. The total pollen sum comprises all the pollen counted (at least 300 pollen grains per sample). The pollen concentrates were mounted in glycerol gel.

\section{RESULTS}

CHRONOLOGY

PREHEATING PLATEAU AND OSL SATURATION

To determine appropriate preheating conditions for $D_{\mathrm{e}}$ estimation, $D_{\mathrm{e}}$ preheating plateau tests were carried out. $D_{\mathrm{e}}$ values were obtained using the SAR method at preheating temperatures of 160,180,200,220,240, 260 and $280^{\circ} \mathrm{C}$ for $10 \mathrm{~s}$. Four aliquots were measured at temperatures. $D_{\mathrm{e}}$ is independent of preheating temperature in the range of $160-280^{\circ} \mathrm{C}$. Therefore, preheating of $260^{\circ} \mathrm{C}$ for $10 \mathrm{~s}$ was employed. The regenerative-dose growth curve and OSL decay curves are illustrated in Figure 3.

DOSE RECOVERY TESTS

In order to test the reliability of the SAR protocol, dose recovery tests were designed for sample gls- 3 and gls-4. The natural OSL signal from a sample was first removed completely by exposing the aliquot to blue light in the OSL reader at room temperature. It was then given a known beta dose before any measurements. This given dose is treated as an unknown natural dose, and then measured using the SAR. Figure 4 shows that the results of dose recovery test and the measured doses are in agreement within error limits with the given dose. This suggests that the SAR protocol is suitable for these samples.

\section{EQUIVALENT DOSE AND AGES}

The $D_{\mathrm{e}}$ averages of all measured aliquots and all dating results are listed in Table 2. The age span of all samples was from 14.77 to $0.72 \mathrm{ka}$, and the error ranged from 7 to $11.2 \%$. The OSL ages are in stratigraphic order (Fig. 2).

$$
\text { AMS }{ }^{14} \mathrm{C} \text { AGES }
$$

At the depth of $144 \mathrm{~cm}$, the radiocarbon age was $8.500 \pm$ $30 \mathrm{ka} \mathrm{BP}$, and the calibrated ${ }^{14} \mathrm{C}$ age was $9.511 \pm 17 \mathrm{cal}$. ka BP. The radiocarbon age was younger than the OSL age $(14.77 \pm$ $1.12 \mathrm{Ka}$ ) for a sample (at the depth of $144 \mathrm{~cm}$ ), the reason might be that a younger plant fragment had entered into the core. Although the core comprised peat, present plant roots can reach the bottom of the core, which can result in the contamination for ${ }^{14} \mathrm{C}$ dating. In an environment which eventually leads to a peat deposit, the energy in the fluvial process is low, so that the sediment can have enough exposure time to light, and the OSL signal can be reset completely. As a result, OSL ages are credible. In this study only OSL ages were used to establish the chronology.

The age of every $3 \mathrm{~cm}$ interval of the core was estimated using linear interpolation or extrapolation between the nearest OSL dates. The bottom (oldest) date was taken from the sample at $144 \mathrm{~cm}(14.77 \pm 1.12 \mathrm{ka})$. The sedimentation rates (Fig. 5) were constructed; the mean sedimentation rate for the entire core was $0.098 \mathrm{~mm} / \mathrm{a}$. According to the five obtained dates, five intervals can be identified: $0-24,24-54,54-85$, $85-113$ and $113-144 \mathrm{~cm}$. The sedimentary rates were 0.33 , $0.06,0.04,0.23$ and $0.52 \mathrm{~mm} / \mathrm{a}$, respectively.

\section{POLLEN ANALYSIS}

All samples in the five units were microscopically analysed for pollen (Fig. 6). Pollen preservation was poor. More than 300 pollen grains were counted for each sample. Nineteen taxa were identified, including the major taxa present in the complete profile: Cyperaceae, Chenopodiaceae, Artemisia, Betula, Picea, 

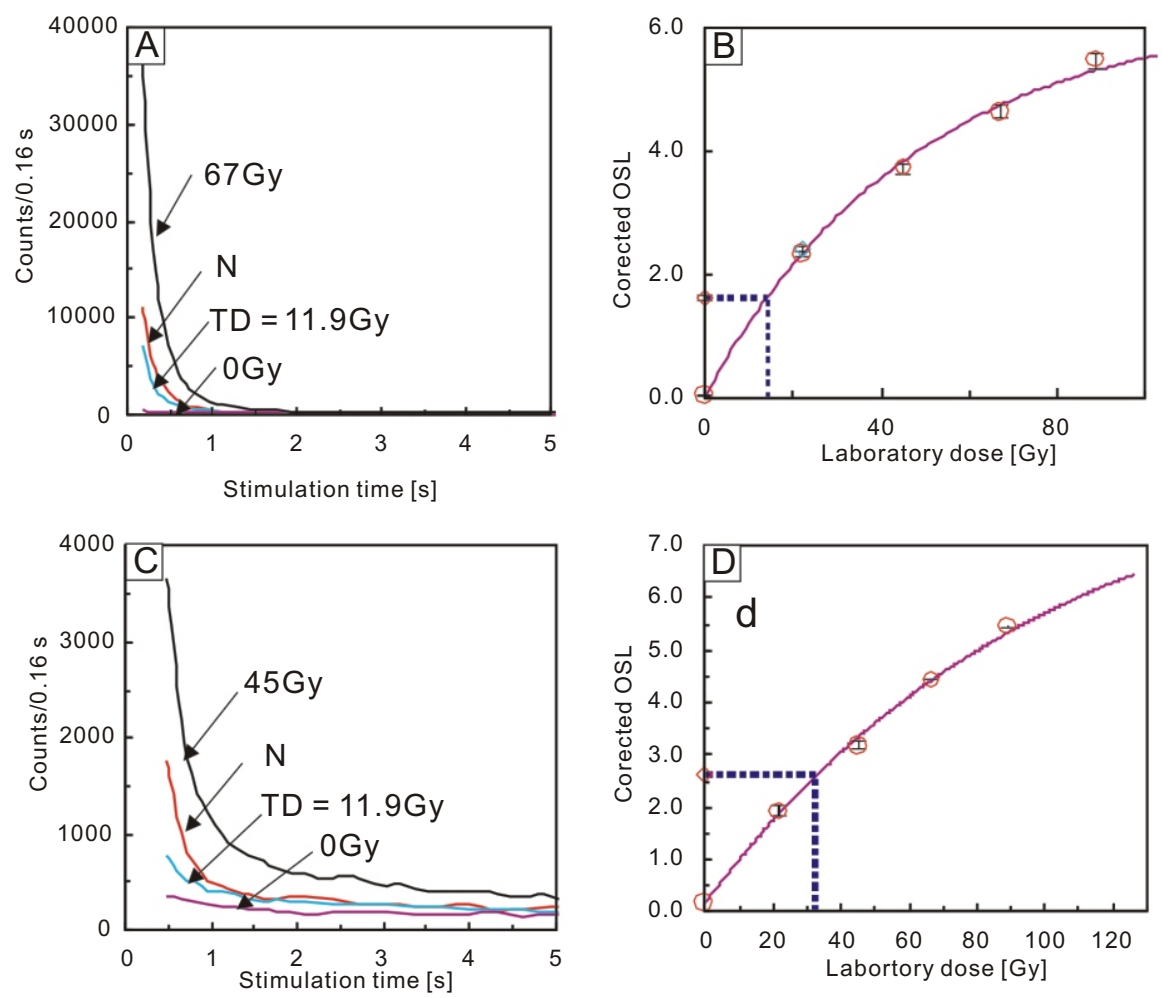

Fig. 3. OSL decay curves and growth curves for sample gls-2 (A, B) and gls-4 (C, D) dwarf shrub. The main $(<1 \%)$ tree pollen were Pinus, Picea, and Betula; the main herbaceous pollen $(93 \%)$ were Cyperaceae (83\%), Gramineae $(0.7 \%)$, Compositae (4.6\%), Chenopodiaceae $(0.7 \%)$, Artemisia $(1.7 \%)$, Ranunculaceae (1.1\%), Rosaceae $(0.6 \%)$, Polygonaceae $(0.7 \%)$, and Geraniaceae $(0.1 \%)$; the main dwarf shrub pollen (3\%) were Elaeagnaceae and Ephedra. According to pollen concentration and species percentages, five local pollen assemblage zones (namely 1-5) could be distinguished from the bottom to the top of the core (Fig. 6).

In Pollen Zone 1 (14.3-14.8 ka), the total pollen concentration was relatively high. Cyperaceae was dominant, other herbaceous species such as Chenopodiaceae, Artemisia, Compositae, Elaeagnaceae and Poaceae being present in relatively high percentages.

In Pollen Zone 2 (14.3-13.2 ka), the total pollen concentration was at its highest. Herbaceous species such as Elaeagnaceae, Artemisia and Compositae were present in relatively high percentages. Total pollen concentration and the proportion of Cyperaceae initially increased and then reached a peak around $13.8 \mathrm{ka}$, while Ranunculaceae, Liliaceae and

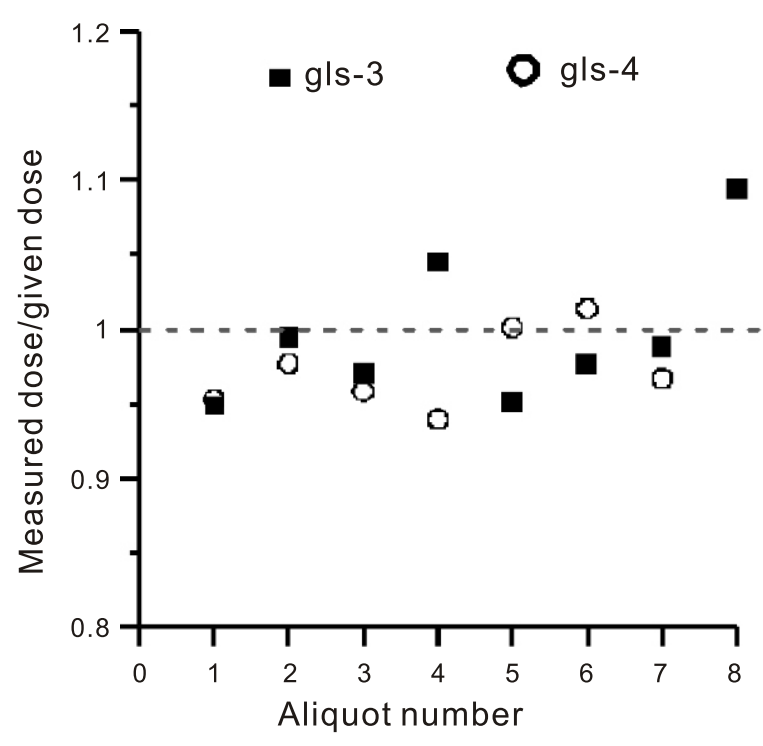

Fig. 4. The results of dose recovery tests for sample gls-3 and gls-4

The dashed line is the ratio of measured dose/given dose

Pinus, Compositae, Ranunculaceae, Rosaceae, Polygonaceae, Poaceae, Ephedra, Elaeagnaceae, Leguminosae, Liliaceae, Cruciferae, Thalictrum, Gentianaceae and Geraniaceae.

Among the 47 samples analysed, there were three types of tree pollen, 14 types of herbaceous pollen, and two types of
Cruciferae pollen decreased. There was almost no Rosaceae or Gentianaceae pollen in this assemblage, and percentages of tree pollen were relatively low.

In Pollen Zone 3 (4.5-13.20 ka), the total pollen concentration was at its lowest. Tree pollen showed a proportional increase in the sequence. The Picea and Pinus pollen percentages were relatively higher than in other pollen zones, and more herbaceous species were present in this assemblage, such as Rosaceae, Gentianaceae, Ephedra and Thalictrum. The proportion of Chenopodiaceae, Elaeagnaceae, Artemisia and Compositae remained relatively high, and locally reached their maximum values.

In Pollen Zone 4 (0.5-4.5 ka), the total pollen concentration started to increase. The proportion of the Compositae, Rosaceae, and Leguminosae pollen gradually decreased, while the proportion of Elaeagnaceae increased.

In Pollen Zone $5(0-0.5 \mathrm{ka})$, the total pollen concentration continued to increase. The proportion of tree pollen gradually decreased, although Cyperaceae pollen was still dominant. Among the herbaceous pollen, Compositae, Rosaceae and Leguminosae kept a stable proportion. Pollen of Elaeagnaceae and Ephedra was not observed.

\section{PROXY ANALYTICAL RESULTS}

The values of TOC, $\delta^{13} \mathrm{C}$, and the ratios of TOC/TN ranged from 6 to $175 \mathrm{mg} / \mathrm{g},-26.92$ to $-25.12 \%$ and 2.99 to 316 , respectively. The values of $\mathrm{Rb}, \mathrm{Ba}$, magnetic susceptibility (MS) and grain size ranged from $98.2-119.8 \mu \mathrm{g} / \mathrm{g}$ to $477.6-409 \mu \mathrm{g} / \mathrm{g}$, 
Environmental radiation measurements and OSL ages

\begin{tabular}{|c|c|c|c|c|c|c|c|c|c|}
\hline $\begin{array}{c}\text { Sam- } \\
\text { ple } \\
\text { no. }\end{array}$ & $\begin{array}{c}\text { Depth } \\
{[\mathrm{cm}]}\end{array}$ & $\begin{array}{c}\text { Water } \\
\text { content } \\
{[\%]}\end{array}$ & $\begin{array}{c}\mathrm{K} \\
{[\%]}\end{array}$ & $\begin{array}{c}\text { Th } \\
{[\mathrm{ppm}]}\end{array}$ & $\begin{array}{c}\mathrm{U} \\
{[\mathrm{ppm}]}\end{array}$ & $\begin{array}{c}\text { Dose rate } \\
{[\mathrm{Gy} / \mathrm{ka}]}\end{array}$ & $\begin{array}{c}D_{\mathrm{e}} \\
{[\mathrm{Gy}]}\end{array}$ & $\begin{array}{c}\text { Age } \\
{[\mathrm{ka}]}\end{array}$ & $\mathrm{Method}$ \\
\hline gls-1 & 24 & 15 & $1.79 \pm 0.07$ & $6.91 \pm 0.19$ & $1.75 \pm 0.13$ & $2.62 \pm 0.15$ & $1.98 \pm 0.13$ & $0.72 \pm 0.07$ & $\mathrm{OSL}$ \\
\hline gls-2 & 54 & 15 & $1.66 \pm 0.07$ & $9.1 \pm 0.24$ & $2.33 \pm 0.17$ & $2.73 \pm 0.13$ & $16.43 \pm 0.74$ & $5.62 \pm 0.46$ & $\mathrm{OSL}$ \\
\hline gls-3 & 85 & 15 & $1.57 \pm 0.06$ & $9.40 \pm 0.24$ & $2.47 \pm 0.17$ & $2.70 \pm 0.13$ & $37.43 \pm 1.13$ & $12.95 \pm 0.96$ & $\mathrm{OSL}$ \\
\hline gls-4 & 113 & 30 & $1.67 \pm 0.06$ & $9.71 \pm 0.26$ & $2.77 \pm 0.18$ & $2.84 \pm 0.14$ & $32.88 \pm 0.46$ & $14.19 \pm 0.98$ & $\mathrm{OSL}$ \\
\hline gls-5 & 144 & 40 & $1.64 \pm 0.06$ & $10.45 \pm 0.27$ & $2.5 \pm 0.19$ & $2.78 \pm 0.14$ & $31.07 \pm 1.05$ & $14.77 \pm 1.12$ & $\mathrm{OSL}$ \\
\hline gls-6 & 144 & - & - & - & - & - & - & $8.500 \pm 30$ & $\mathrm{AMS}{ }^{14} \mathrm{C}$ \\
\hline
\end{tabular}

All of the samples were dated using quartz OSL; sample gls- 5 was dated using $A M S^{14} \mathrm{C}$; the elevation refers to that of the sample location; for each sample, 12 aliquots were measured for $D_{\mathrm{e}}$ determination

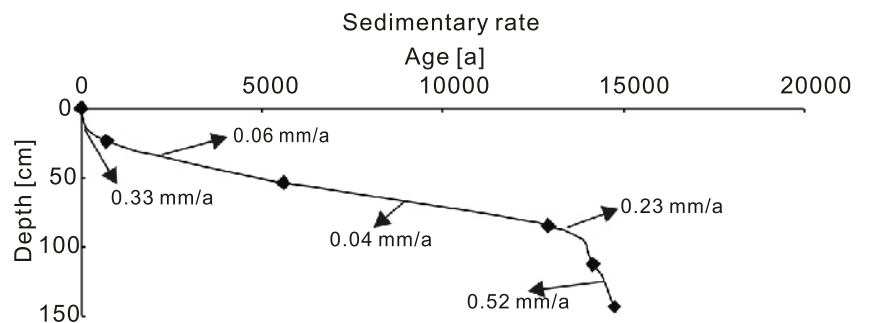

Fig. 5. Sedimentation rates based on OSL dating and depth of the alpine wetland sediment core
0.49 to $0.92,29.8$ to $71.59 \times 10^{-8} \mathrm{~m}^{3} / \mathrm{kg}$ (SI system) and 35.5 to $64.5 \mu \mathrm{m}$, respectively. Five sedimentary units, from Units 1 to 5 in ascending order, were distinguished based on sedimentary textures. The values of TOC, $\delta^{13} \mathrm{C}$, the ratios of TOC/TN, grain size distribution, MS, Ba and Rb variation are show in Figure 7.

Unit 1: 14.3-14.8 ka (116-147 cm). The values of TOC decrease and reach their minimum value at $116 \mathrm{~cm}(14.3 \mathrm{ka})$; the $\delta^{13} \mathrm{C}$ and MS, decrease first, and then increase. The ratio value of TOC/TN shows the opposite trend. The value of $\mathrm{Ba}$ shows multiple fluctuations. Two abrupt changes occur at $128 \mathrm{~cm}$ (14.5 ka) and $137 \mathrm{~cm}(14.6 \mathrm{ka})$.

Unit 2: 13.2-14.3 ka $(86-116 \mathrm{~cm})$. The values of TOC initially increase and then became stable. The values of $\delta^{13} \mathrm{C}$ and $\mathrm{Ba}$ first decrease then increase. The MS, Rb and grain size decrease slightly. Higher TOC and lower $\delta^{13} \mathrm{C}$ values were found at the depth of $107 \mathrm{~cm}(13.9 \mathrm{ka})$.

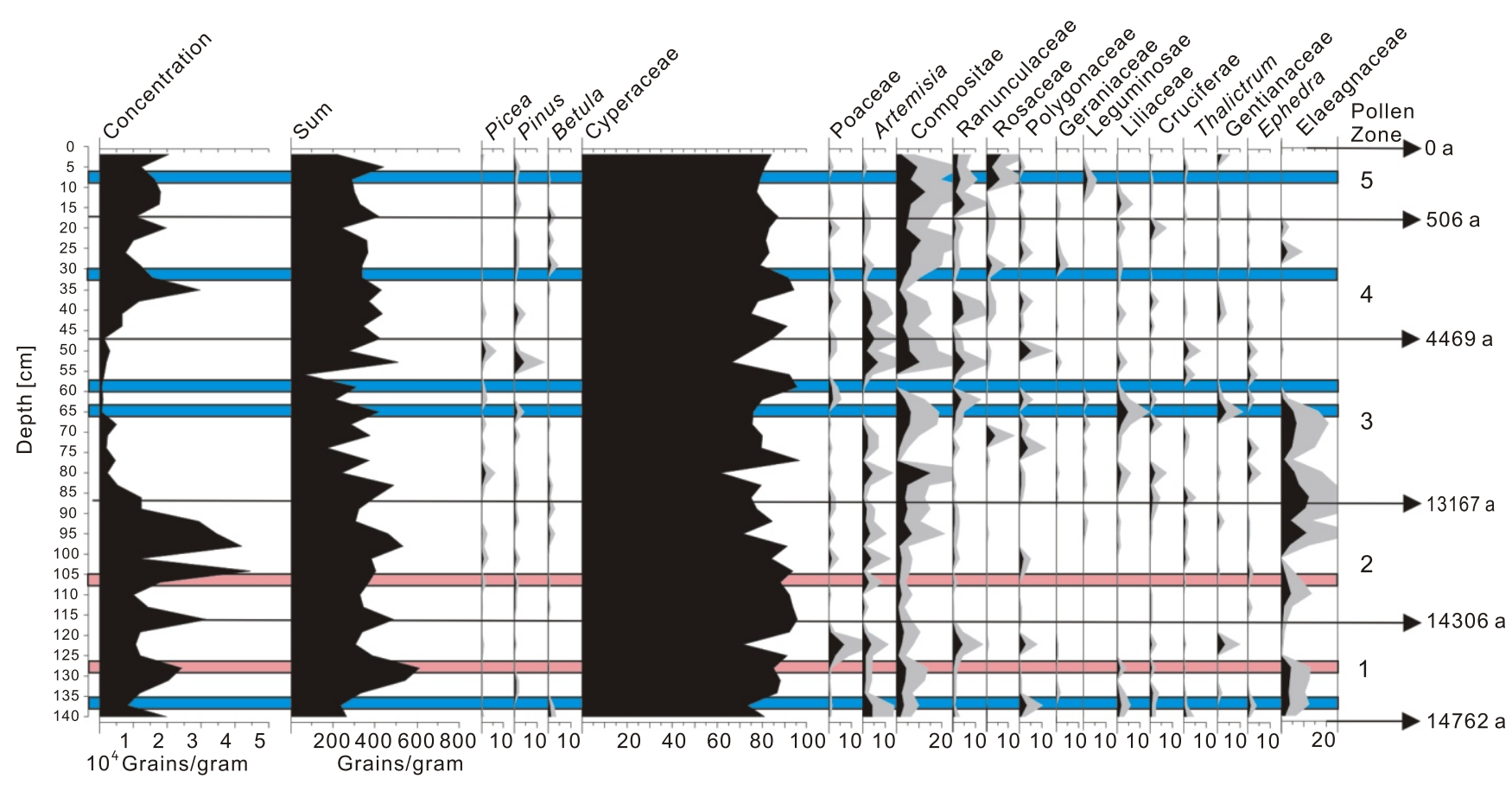

Fig. 6. Pollen percentages of major taxa in $\mathbf{4 7}$ pollen samples collected from the alpine wetland

Pink bands indicate abrupt warm climate events; blue bands indicate abrupt cold climate events 


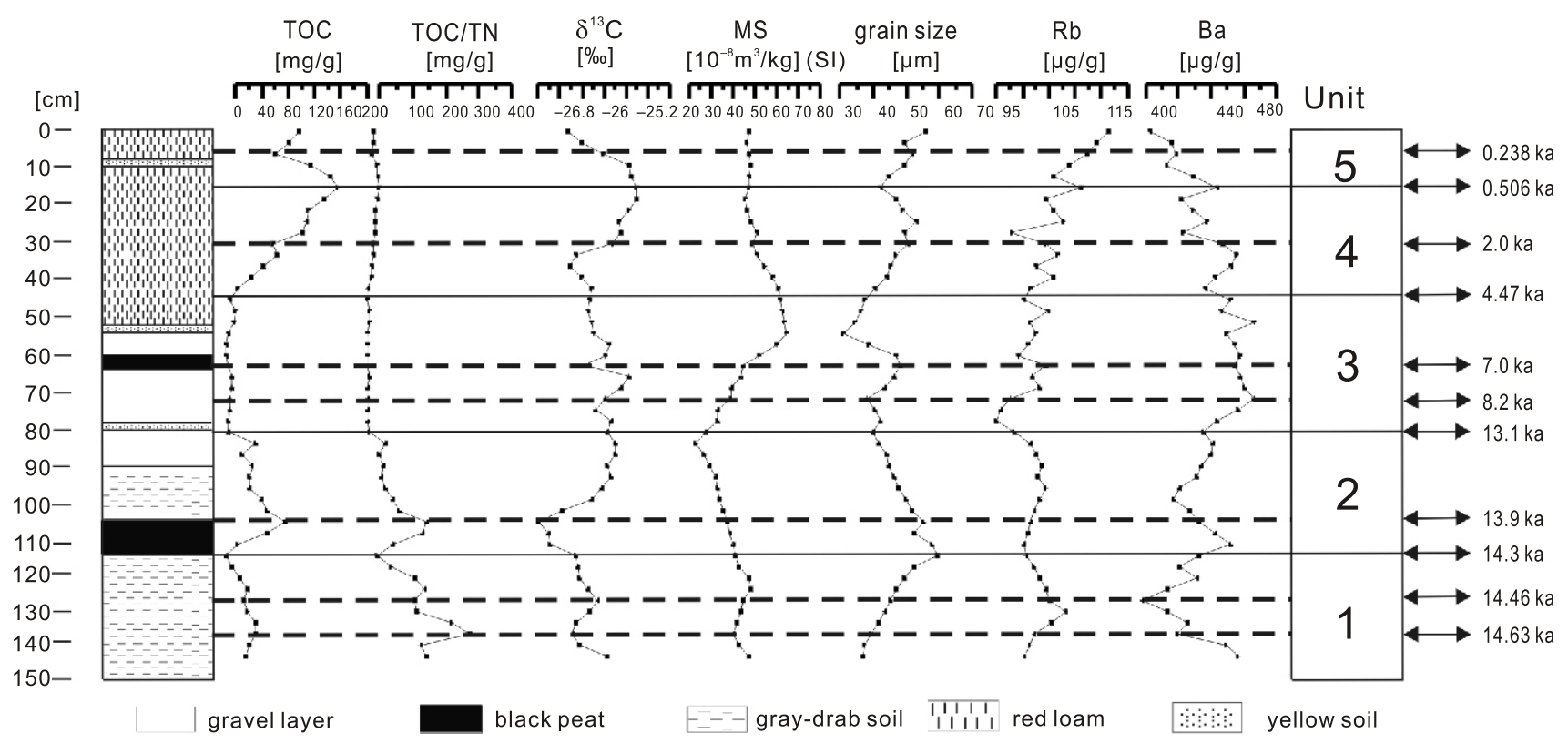

Fig. 7. Stratigraphic columns and variations of TOC content, $\delta^{13} \mathrm{C}$ values, MS, grain size, $\mathrm{Rb}, \mathrm{Sr}$, Ba, and TOC/TN ratios

Unit 3: 4.469-13.167 ka $(47-86 \mathrm{~cm})$. The value of TOC is the lowest in the successions, but MS is higher and reaches its highest value in this sequence at $59 \mathrm{~cm}(7.0 \mathrm{ka})$. Grain size decreases and also reaches its lowest value at $59 \mathrm{~cm}(7.0 \mathrm{ka})$ in this sequence, implied stronger currents, more rapid mineral matter weathering, and higher precipitation at the coring site. The $\mathrm{Rb}$ content show fluctuates. An abrupt decrease of $\delta^{13} \mathrm{C}$ values, higher MS and Ba contents is found at $65 \mathrm{~cm}(8.2 \mathrm{ka})$.

Unit 4: $0.51-4.4 \mathrm{ka}(17-47 \mathrm{~cm})$. Compared to the previous unit, the value of TOC increases and reach its highest value at $47 \mathrm{~cm}(4.469 \mathrm{ka})$. The $\delta^{13} \mathrm{C}$ values also increase with age. MS decreases while grain size increases. The trends of $\mathrm{Rb}$ and $\mathrm{Ba}$ are as in Unit 3. The $\delta^{13} \mathrm{C}$ values abruptly increase and higher MS content is at $32 \mathrm{~cm}(2.0 \mathrm{ka})$.

Unit 5: $0-0.51 \mathrm{ka}(0-17 \mathrm{~cm})$. The value of TOC first decreases and then starts to increase at $8 \mathrm{~cm}(0.24 \mathrm{ka})$. The $\delta^{13} \mathrm{C}$ values and $\mathrm{Ba}$ content gradually decrease while the grain size and $\mathrm{Rb}$ increase. MS stays stable. An inflection point in TOC was recorded at $8 \mathrm{~cm}(0.24 \mathrm{ka})$.

\section{DISCUSSION AND CONCUSIONS}

The combined sediment proxies of grain size, magnetic susceptibility, TOC, $\delta^{13} \mathrm{C}, \mathrm{Rb}, \mathrm{Ba}$, the ratios of TOC/TN, and pollen were used to reconstruct past environmental change (the last $\sim 14.8 \mathrm{ka}$ ) on the QTP in China. The results are interpreted and discussed below, from the oldest sediments to the youngest ones, within lithological units 1 through 5 .

Unit 1 (14.3-14.8 ka): the increase in grain size and Ba content, and the MS, TOC and Rb decrease, suggests a relatively cold and wet environment, consistent with other proxy time-series on the northeastern QTP (Wischnewski et al., 2011). The moisture-loving tree Betula and herbaceous Cyperaceae were present in relatively large proportions despite lower pollen concentrations, suggesting high relative humidity prevailed. However, Cyperaceae pollen showed a sharp decrease around 14,300 year, implying a sudden cold or arid event.

Unit $2(13.2-14.3 \mathrm{ka})$ : overall high percentages of organic material and low $\delta^{13} \mathrm{C}$ value could be interpreted as indicative of warmer and wetter conditions at this site, as pollen preservation and abundance increased in Unit 2. Lower percentages of degraded pollen and higher pollen influx were recorded, suggesting a shift to low energy depositional processes as well as an increase in vegetation. The wetland taxon Cyperaceae dominated in this unit. The recorded rising influx of herbaceous, namely Amaranthaceae, Compositae, Poaceae and Polygonaceae, suggest higher biological productivity for the alpine wetland and surrounding uplands, indicating an optimum period for wetland plant growth.

Unit $3(4.47-13.17 \mathrm{ka})$ : at the time of the lowest value of TOC, when the $\delta^{13} \mathrm{C}$ value and grain size increased first and then decreased, the sedimentary rate was $0.04 \mathrm{~mm} / \mathrm{a}$. The sediment proxy results showed that sedimentary deposition nearly came to a halt. The lowest numbers of pollen grains and TOC value of the profile were found in these sand layers. Therefore, there are two possible climatic scenarios for this interval in the QTP region: utmost cold and dry or utmost wet and warm. However, the increase of MS indicates that the sand layers recorded a shift from wetland depositional system to a fluvial depositional system. Poor pollen preservation in this unit is also an indicator of moving water, that could prevent their deposition and preservation (Solomon et al., 1982). The wetland taxa Cyperaceae and Compositae, Poaceae, are well-represented in the pollen record. The uplands were likely a mix of grasses and woody shrubs.

Unit 4 (0.51-4.47 ka): an increase in the number of pollen grains, pollen preservation, organics, and $\delta^{13} \mathrm{C}$ value in a red loam layer indicated a change to a relatively low-energy depositional environment (Figs. 3 and 4). The quieter water dynamics (compared with the previous unit) resulted in the accumulation of fine organic sediment, indicating a shift in precipitation. The proxy results indicated colder and dryer conditions. The Artemisia, Polygonaceae, Ephedra, Elaeagnaceae, and Liliaceaepollen show a trend of increase and were probably associated with dry soil and less precipitation.

Unit $5(0-0.56 \mathrm{ka})$ : this unit recorded a drop in $\delta^{13} \mathrm{C}$ and increase in grain size, indicating a higher air temperature. The dominant taxon was also Cyperaceae, but Compositae, Rosaceae, Leguminosae increased. The combined pollen and other proxies also indicate that habitat shift from a wetland to a 
meadow environment took place in response to drying and warming periods during the last $0.5 \mathrm{ka}$. As an effect of warmer and drier scenario on the succession of plant communities, species richness was changed (Henderson-Sellers et al., 1995). In the ongoing warming and drying future (IPCC, 2007), plants of the Cyperaceous in alpine wetlands might be under threat.

This study showed that six major vegetational and climate characters could be distinguished, including (1) an alpine wetland that started to develop at $14.8 \mathrm{ka}$ in the QTP region; (2) a shift at 13.2 ka to conditions of higher effective moisture and a stepwise warmer climate sustained from $13.2 \mathrm{ka}$ to $4.5 \mathrm{ka}$; (3) a shift to a significantly colder and drier phase at $4.4 \mathrm{ka}$; (4) severally warm and dry climate over the last $0.5 \mathrm{ka}$; (5) abrupt cold climate events happened at 14.6, 8.2, 7.0, 2.0 and $0.2 \mathrm{ka}$, and abrupt warm climate events happened at 14.5 and $13.9 \mathrm{ka}$ (Figs. 6 and 7); and (6) the Cyperaceae were dominant throughout. With a significant positive correlation between the Cyperaceae pollen and the TOC values.

Some researchers have concluded that the highest levels of inundation were reached between the 13,000 $\mathrm{yr}$ BP and $4000 \mathrm{yr}$ BP (Kashiwaya et al., 1995) while the first half (10.8-4.4 cal. ka BP) of the Holocene was characterized by warm and wet conditions. Then climate became colder and drier in the second half (4.4-0 ka) of the Holocene (Shi et al., 1993; Fleitmann et al., 2003; Morrill et al., 2003; Wang et al., 2005; Herzschuh, 2006). Our studies of this alpine wetland suggests that there were more large fluvial discharge events during mid-Holocene than during the late Holocene. These results were consistent with previous studies (Berg and Loutre, 1991; Wu et al., 2007) and successfully explain the influence of the Indian summer monsoon during the early Holocene and of the SE Asian summer monsoon and the westerlies during the mid-Holocene in the centre of the QTP (e.g., An et al., 2000; Fleitmann et al., 2003; Wang et al., 2005; Herzschuh, 2006; Chen et al., 2008; Yang and Scuderi, 2010).
Some researchers have recognised cold events between 8.7 and 8.3 cal. ka BP (Hu et al., 1999), 7.0 cal. ka BP, 2.2 cal. ka BP (Wischnewski et al., 2011), based on a pollen record from Lake Zigetang on the Central Tibetan Plateau. The most pronounced cold events (with temperature below those of the present) occurred on the Central Tibetan Plateau between 8.7-8.3 and 7.4 cal. ka BP (Van Campo and Gasse, 1993; Gasse et al., 1996) and the 8.2 ka cold event was recorded in Greenland ice cores (Alley et al., 1997). Dry events happened at about $4 \mathrm{ka}$ BP and $2 \mathrm{ka}$ BP to the south of the Qinghai-Tibetan Plateau (Zhao, 2009). There is evidence of warm or cold/wet or dry events. However, our study has not detected periods of abrupt climate change, which might be influenced by the microcirculation systems from a different region (An et al., 2006; Yang et al., 2008).

Multiproxy studies of alpine wetland on China's QTP are rare. In this study, OSL dating, pollen, organic content, grain size, and MS have been used to reconstruct the past environmental and climate history of the QTP. These perennially wet ecosystems proved to be effective archives of past vegetational and climate change. Sediment proxies from the study site recorded an unsteady warming tendency in early Holocene, warm-humid conditions in the mid Holocene, and cold and dry conditions in the late Holocene.

Acknowledgements. We thank Doctors Xiangjun Liu, Luchun Yang and Guangping Xu for their assistance in the laboratory. This study was sponsored by The National Key Technology R\&D Program (Grant No: 2007BAC30) and One-hundred Talent Project of CAS(A0961). We are grateful to Prof. Zhuo Zheng and one anonymous reviewer as well as to the editors W. Granoszewski and T. Peryt for valuable comments and suggestions that helped to improve the manuscript.

\section{REFERENCES}

Alley R.B., Mayewski P., Sowers T., Stuiver M., Taylor K.C., Clark P.U. (1997) Holocene climate instability: a prominent, widespread event 8200 yr ago. Geology, 25: 463-486.

An C.B., Feng Z.D., Barton L. (2006) Dry or humid? Mid-Holocene humidity changes in arid and semi-arid China. Quaternary Science Reviews, 25 (3-4): 351-361.

An Z.S., Porter S.C., Kutzbach J.E., Zhou W.J. (2000) Asynchronous Holocene optimum of the East Asian monsoon. Quaternary Science Reviews, 19 (8): 743-762.

Berger A., Loutre M.F. (1991) Insolation values for the climate of the last 10 million years. Quaternary Science Reviews, 10 (4): 297-317.

Bian Y., Jian Z., Weng C., Kuhnt W., Bolliet T., Holbourn A. (2011) A palynological and palaeoclimatological record from the southern Philippines since the Last Glacial Maximum. Chinese Science Bulletin, 56: 2359-2365.

Chen F.H., Yu Z.C., Yang M.L., Ito E., Wang S.M., Madsen D.B., Huang X.Z., Zhao Y., Sato T., Birks H.J.B., Boomer I., Chen J.H., An C.B., Wünnemann B. (2008) Holocene moisture evolution in arid central Asia and its out-of-phase relationship with Asian monsoon history. Quaternary Science Reviews, 27: 351-364.
Fleitmann D., Burns S., Mudelsee M. (2003) Holocene forcing of Indian monsoon recorded in a stalagmite from southern Oman. Science, 300: 1737-1739.

Gasse F., Fontes J.C., Van Campo E., Wei K. (1996) Holocene environmental changes in Bangong Co Basin (Western Tibet). Palaeogeography, Palaeoclimatology, Palaeoecology, 120: 79-92.

Herzschuh U. (2006) Palaeo-moisture evolution in monsoonal Central Asia during the last 50,000 years. Quaternary Science Reviews, 25: 163-178.

Herzschuh U., Winter K., Wünnemann B., Li S. (2006) A general cooling trend on the central Tibetan Plateau throughout the Holocene recorded by the Lake Zigetang pollen spectra. Quaternary International, 154-155: 113-121.

Henderson-Sellers A., McGuffie K. (1995) Global climate models and "dynamic" vegetation changes. Global Change Biology, 1: 63-76.

Hu F., Slawinski D., Wright H.E., Boedigheimer A. (1999) Abrupt changes in North American climate during Early Holocene times. Nature, 400: 437-440.

IPCC (Intergovernmental Panel on Climate Change) (2007) Climate Change 2007 - The Physical Science Basis: Working 
Group I Contribution to the Fourth Assessment Report of the IPCC. Cambridge University Press, Cambridge.

Kashiwaya K., Masuzawa T., Morinaga H., Yaskawa K., Yuan B.Y., Liu J.G., Gu Z.Y. (1995) Changes in hydrological conditions in the central Qing-Zang (Tibetan) Plateau inferred from lake bottom sediments. Earth and Planetary Science Letters, 135: 31-39.

Kim H., Kim J. (2010) A 2000-year environmental history of the Upo Wetland on the Korean Peninsula. Journal of Paleolimnology, 44: 189-202.

Lai Z.P. (2010) Chronology and the upper dating limit for loess samples from Luochuan section in the Chinese Loess Plateau using quartz OSL SAR protocol. Journal of Asian Earth Sciences, 37: $176-185$.

Lai Z.P., Wintle A.G., Thomas D.S.G. (2007) Rates of dust deposition between $50 \mathrm{ka}$ and $20 \mathrm{ka}$ revealed by OSL dating at Yuanbao on the Chinese Loess Plateau. Palaeogeography, Palaeoclimatology, Palaeoecology, 248: 431-439.

Lai Z.P., Zöller L., Fuchs M., Brückner H. (2008) Alpha efficiency determination for OSL of quartz extracted from Chinese loess. Radiation Measurements, 43: 767-770.

Lister G.S., Kelts K., Zao C., Yu J., Niessen F. (1991) Lake Qinghai, China: closed-basin lake levels and the oxygen isotope record for ostracoda since the latest Pleistocene. Palaeogeography, Palaeoclimatology, Palaeoecology, 84: 141-162.

Liu F., Zhang Y., Feng Z., Hou G., Zhou Q., Zhang H. (2010) The impacts of climate change on the Neolithic cultures of Gansu-Qinghai region during the late Holocene Megathermal. Journal of Geographical Sciences, 20: 417-430.

Margielewski W., Kołaczek P., Michczyński A., Obidowicz A. Pazdur A. (2011) Record of the Meso- and Neoholocene palaeoenvironmental changes in the Jesionowa landslide peat bog (Beskid Sądecki Mts., Polish Outer Carpathians). Geochronometria, 38: 138-154.

Mesnage V., Bonneville S., Laignel B., Lefebvre D., Dupont J.P., Mikes D. (2002) Filling of a wetland (Seine estuary, France): natural eutrophication or anthropogenic process? A sedimentological and geochemical study of wetland organic sediments. Hydrobiologia, 475-476 (1): 423-425.

Morrill C., Overpeck J.T., Cole J.E. (2003) A synthesis of abrupt changes in the Asian summer monsoon since the last deglaciation. Holocene, 13: 465-476.

Murray A.S., Wintle A.G. (2000) Luminescence dating of quartz using an improved single-aliquot regenerative-dose protocol. Radiation Measurements, 32: 57-73.

Prescott J.R., Hutton J.T. (1994) Cosmic ray contribution to dose rates for luminescence and ESR dating: large depths and long-term time variations. Radiation Measurements, 23: 497-500.

Shi Y.F., Kong Z.Z., Wang S.M. (1993) Mid-Holocene climates and environments in China. Global and Planetary Change, 7: 233-291.

Solomon A.M., Blasing T.J., Solomon J.A. (1982) Interpretation of floodplain pollen in alluvial sediments from an arid region. Quaternary Research, 18: 52-71.
Van Campo E., Gasse F. (1993) Pollen- and diatom-inferred climatic and hydrological changes in the Sumxi Co Basin (western Tibet) since 13,000 yr BP. Quaternary Research, 39: 300-313.

Wang J., Zhu L., Nishimura M., Testsuya M. (2009) Spatial variability and correlation of environmental proxies during the past 18,000 years among multiple cores from Lake Pumoyum Co, Tibet, China. Journal of Paleolimnology, 42: 303-315.

Wang M. (2005) A Study on Ecology and Environment Process of Cenozoic Qinghai-Tibet Plateau Hinterland (in Chinese with English abstract). Unpublished Ph.D. dissertation, Chengdu University of Technology.

Wang Y., Cheng H., Edwards R.L. (2005) The Holocene Asian Monsoon: links to solar changes and North Atlantic climate. Science, 308: 854-857.

Wei H.C., Ma H.Z., Zheng Z., Pan A.D., Huang K.Y. (2010) Modern pollen assemblages of surface samples and their relationships to vegetation and climate in the northeastern Qinghai-Tibetan Plateau, China. Review of Palaeobotany and Palynology, 162: 168-182.

Wischnewski J., Mischke S., Wang Y., Herzschuh U. (2011) Reconstructing climate variability on the northeastern Tibetan Plateau since the last Lateglacial multi-proxy, dual-site approach comparing terrestrial and aquatic signals. Quaternary Science Revues, 30: 82-97.

Wu Y., Andreas L., Bernd W., Li S., Wang S. (2007) Holocene climate change in the Central Tibetan Plateau inferred by lacustrine sediment geochemical records. Science in China Series D: Earth Sciences, 50: 1548-1555.

Yang X., Scuderi L. (2010) Hydrological and climatic changes in deserts of China since the Late Pleistocene. Quaternary Research, 73: 1-9.

Yang X., Zhu B., Wang X., Lu Y. (2008) Late Quaternary environmental changes and organic carbon density in the Hunshandake Sandy Land, eastern Inner Mongolia, China. Global and Planetary Change, 61: 70-78

Zhao C.H. (2009) Climate Evolution of Holocene in Eastern Aisa and Its Quantitative Analysis (in Chinese with English abstract). Nanjing University.

Zhao K. (1999) Marshes and swamps of China: a compilation (in Chinese). Beijing, Science Press of China.

Zhao Z., Qiao Y., Wang S., Jiang F. (2008) Geological characteristics and evolution of the eastern Qinghai-Tibetan plateau since the late Cenozoic. Frontiers of Earth Science, 2 (2): 209-216.

Zhu L., Zhen X., Wang J., Lü H., Xie M., Kitagawa H., Possnert G. (2009) A 30,000-year record of environmental changes inferred from Lake Chen Co, Southern Tibet. Journal of Paleolimnology, 42 (3): 343-358.

Zhu L., Peng P., Xie M., Wang J., Frenzel P., Wrozyna C., Schwalb A. (2010) Ostracod-based environmental reconstruction over the last 8,400 years of Nam Co Lake on the Tibetan plateau. Hydrobiologia, 648 (1): 157-174.

Zhu L.P., Li Y.F., Li B.Y. (2002) The ostracod assemblages and their environmental significance in the Chen Co area, southern Tibet in recent 1400 years. Journal of Geographical Sciences, 12 (4): 451-459. 